\title{
The Psychological Impact of COVID-19 Disease is more Severe on Intensive Care Unit Healthcare Providers: A Cross-sectional Study
}

\author{
Kemal Tolga Saracoglư ${ }^{1}$, Tahsin Simsek ${ }^{1}$, Selime Kahraman ${ }^{2}$, Elif Bombaci ${ }^{1}$, Özlem Sezen ${ }^{1}$, Ayten Saracoglu ${ }^{3}$, \\ Recep Demirhan ${ }^{2}$ \\ ${ }^{1}$ Clinic of Anesthesiology and Intensive Care, ${ }^{2}$ Clinic of Thoracic Surgery, Health Sciences University Kartal Dr. Lutfi Kirdar Training and Research \\ Hospital, ${ }^{3}$ Clinic of Anesthesiology and Intensive Care, Marmara University Pendik Training and Research Hospital, Istanbul, Turkey
}

\begin{abstract}
Objective: Fear, anxiety, depression and sleep deprivation are common mental health disorders in COVID-19 disease. We aimed to analyse the risk for healthcare providers during COVID-19 pandemic in a university hospital. Methods: Anesthesiologists, nurses and nurse anesthetists were invited to fill out the survey. The survey was consist of questions from "The Fear of COVID-19 Scale", 'Patient Health Questionnaire” and "Pittsburgh Sleep Quality Index" (PSQI). Each question was worth a point.

Results: The data of 208 participants were analyzed. Mean age was $29 \pm 7.748$ years, $72.1 \%$ were male, $67.3 \%$ were nurses, $62 \%$ were working in intensive care units, 38\% were in hospital wards, $62 \%$ of all participants were living alone. Moderate depression was the most frequently detected outcome ( $\mathrm{n}=90,43.3 \%$ ). Mean The Fear of COVID-19 Scale for all participants was $18.56 \pm 7.731$. The mean PSQI of patients was $6.18 \pm 4.356$ with a $45.7 \%$ rate of poor sleep quality. PSQI was found significantly higher in nurses $(7.1 \pm 4.7, p=0.000)$. Nurses were the group with the highest deterioration in sleep quality $(53.6 \%, p=0.003)$. The rate of moderate-to-severe depressive symptoms was significantly higher in intensive care unit nurses and physicians $(p=0.018)$. PSQI score was found significantly higher in intensive care unit nurses and physicians than hospital ward co-workers $(7.02 \pm 4.59$ vs. $4.81 \pm 3.57$ respectively, $p=0.001$ ). A significant positive correlation was observed between PSQI and The Fear of COVID-19 Scale total score in all patients $(p<0.005)$.

Conclusion: Depression, anxiety, fear and sleep disorders may occur in healthcare workers during COVID-19 outbreak. Intensive care unit nurses were at highest risk.
\end{abstract}

KEY WORDS: COVID-19; Mental health; Intensive care unit; Pandemic.

\section{INTRODUCTION}

COVID-19 is a highly infectious disease that occurs with Severe Acute Respiratory Syndrome Coronavirus 2 virus. World Health Organization announced on 11 March 2020 that this disease turned into a pandemic [1]. COVID-19 disease causes Adult Respiratory Distress Syndrome and multiple organ failure, leading to death. The low predictability and uncertainty of COVID-19 not

Received: May 12, 2020 / Revised: July 13, 2020

Accepted: August 10, 2020

Address for correspondence: Tahsin Simsek

Clinic of Anesthesiology and Intensive Care, Health Sciences University Kartal Dr. Lutfi Kirdar Training and Research Hospital, Cevizli Mh Semsi Denizer Cad. E-5 Karayolu Cevizli Mevkii, 34890 Kartal, Istanbul, Turkey

E-mail: simsektahsin2017@gmail.com

ORCID: https://orcid.org/0000-0002-3068-4998 only threatens people's physical health, but also affects people's mental health, especially in terms of emotion and cognition [2]. Healthcare providers taking care for COVID-19 patients also have concerns about their mental health, psychological adjustment and recovery [3]. As they face a potential threat in hospital, behaviors appear to avoid contact with patients having pneumonia-like symptoms. This may lead to stress, fear, sleep disturbances, and long-term depression. Besides, negative emotions can reduce the immune function and affect the balance of normal physiological mechanisms [4].

Fears, anxiety and depression are common psychological symptoms reported in outbreaks. The main reasons for these symptoms include changes in the daily routine, uncertainty involving a person's job and financial security, well-being of their loved ones, treatment process

(c) This is an Open-Access article distributed under the terms of the Creative Commons Attribution Non-Commercial License (http://creativecommons.org/licenses/by-nc/4.0) which permits unrestricted non-commercial use, distribution, and reproduction in any medium, provided the original work is properly cited. 
and information about the disease [5]. Post traumatic stress symptoms may also occur during outbreaks. The fear of COVID-19 scale is a measurement associated with anxiety, stress and depression. Therefore this scale was accepted as an appropriate test to assess the effects of the outbreak on mental health [6].

Several reports from different countries elucidated that mental well-being has been severly affected during COVID-19 outbreak $[7,8]$. However relevant psychosocial consequences may differ in modern society. Our aim in this cross-sectional study was to analyse the risk for depression, posttraumatic stress disorders and sleep disturbances in healthcare workers who are in contact with COVID-19 patients in our hospital. Our hypothesis was that healthcare professionals can be identified and directed for medical assistance in the early period.

\section{METHODS}

Following the Health Sciences University Ethics Committee approval (protocol no: 13894, date: 29/04/ 2020), anesthesiologists, nurses, nurse anesthetists and staff working in the wards and intensive care units where COVID-19 patients were treated in our hospital were invited to participate in our survey. Participants consisted of healthcare professionals working in the Anesthesiology and Intensive care clinics.

Healthcare Providers with potential direct contact to COVID-19 were working in Intensive Care Units or COVID-19 hospital wards. The other healthcare professionals were taking care of non-COVID patients.

The demographic characteristics of the participants were recorded after obtaining their written informed consent. The questionnaires were given to the participants in printed form and they were asked to fill in. The questions of 3 tests were included in the survey. All of the questionnares were valid and reliable according to the literature.

- Patient Health Questionnaire (PHQ-9) $[9,10]$

- Pittsburgh Sleep Quality Index (PSQI) [11]

- The Fear of COVID-19 Scale [12] were performed.

\section{Patient Health Questionnaire}

The PHQ-9 is a self-administered survey which is consist of 9 questions. Its diagnostic validity was confirmed as a depression-screening tool. The survey is applied to detect major depressive disorders [13]. Each question seeks answer for the frequency of a particular depressive symptom during the last two weeks. For scoring, we added up all checked boxes on PHQ-9. For every checked box we scored as: Not at all = 0; Several days $=1$; More than half the days $=2 ;$ Nearly every day $=3$. Interpretation of total scores was performed as: $1-4$ minimal depression, 5-9 mild depression, 10-14 moderate depression and 1527 severe depression.

\section{Pittsburgh Sleep Quality Index}

The PSQI is the most frequently used self-reported instrument to determine the pattern and quality of sleep over a one-month period [14]. The PSQI is a measurement for global insomnia and sleep symptoms. An individual's subjective perception of sleep can be assessed. Seven components are categorized: sleep duration, latency, quality, efficiency, medication and disturbances, with daytime dysfunction [15]. The usual sleeping habits were evaluated. Nine different questions were asked. Each question was scored within itself. Global PSQI Score has been calculated. It consists of 19 self-rating items that can be into, including subjective sleep.

\section{The Fear of COVID-19 Scale}

The scale has psychometric properties and was developed to screen for fear of COVID-19. It consists of 7 questions which explore the fear of the participants about COVID-19. Each question was scored between 1 and 5 . The items are generated by expert evaluations and participant interviews [12]. The scale is used to predict positive behavior change. This instrument is a rapid way to understand the fear of healthcare providers during the outbreak. Healthcare providers who refused to participate in the survey were excluded.

\section{Statistical Analysis}

Data obtained from the study were analyzed using IBM SPSS Statistics 26 (IBM Co., Armonk, NY, USA). Average, standard deviation, median lowest, highest, frequency and ratio values were used in the descriptive statistics of the data. The distribution of variables was measured by the Kolmogorov - Smirnov test. In the analysis of quantitative independent data, Kruskal-Wallis, Mann - Whitney $U$ test were used. Posthoc analyzes were performed with Mann - Whitney $U$ test, and when it is required Bonferroni correction was performed. Chi-square test was used in the 
analysis of qualitative independent data. Spearman correlation test was used for the correlation analysis. A value of $p<0.05$ was considered statistically significant.

\section{RESULTS}

We invited 500 healthcare providers in our hospital. A total of 220 participants had a positive response and filled out the questionnaire. Missing participant data refered to

Table 1. Demographic data of the participants, duration of professional experience, family information and analysis of responses

\begin{tabular}{|c|c|c|}
\hline Variable & Min-Max & Value \\
\hline Age (yr) & $17.0-58.0$ & $29 \pm 7.748$ \\
\hline \multicolumn{3}{|l|}{ Sex } \\
\hline Female & & $58(27.9)$ \\
\hline Male & & $150(72.1)$ \\
\hline Professional experience & $2 \mathrm{mo}-37.0 \mathrm{yr}$ & $6.16 \pm 7.502$ \\
\hline Anesthesiologists & & $34(16.3)$ \\
\hline Nurses & & $140(67.3)$ \\
\hline Nurse anesthetists & & $34(16.3)$ \\
\hline \multicolumn{3}{|l|}{ Work area } \\
\hline ICU & & $129(62.0)$ \\
\hline Hospital ward & & $79(38.0)$ \\
\hline \multicolumn{3}{|l|}{ Sharing home with others } \\
\hline No & & $59(62.0)$ \\
\hline Yes & & $149(38.0)$ \\
\hline \multicolumn{3}{|l|}{ Children } \\
\hline No & & $163(62.0)$ \\
\hline Yes & & $45(38.0)$ \\
\hline Number of children & $1.0-3.0$ & $1.59 \pm 0.583$ \\
\hline \multicolumn{3}{|c|}{ Direct contact to COVID-19 patients } \\
\hline No & & $57(62.0)$ \\
\hline Yes & & $151(38.0)$ \\
\hline Fear Scale 1st Question & $1.0-5.0$ & $3.19 \pm 1.455$ \\
\hline Fear Scale 2nd Question & $1.0-5.0$ & $3.28 \pm 1.440$ \\
\hline Fear Scale 3rd Question & $1.0-5.0$ & $1.98 \pm 1.286$ \\
\hline Fear Scale 4th Question & $1.0-5.0$ & $2.77 \pm 1.416$ \\
\hline Fear Scale 5th Question & $1.0-5.0$ & $2.92 \pm 1.409$ \\
\hline Fear Scale 6th Question & $1.0-5.0$ & $2.42 \pm 1.462$ \\
\hline Fear Scale 7th Question & $1.0-5.0$ & $2.19 \pm 1.340$ \\
\hline Total score & $7.0-35.0$ & $18.56 \pm 7.731$ \\
\hline \multicolumn{3}{|l|}{ PHQ-9 } \\
\hline Minimal & & $21(10.1)$ \\
\hline Mild & & $63(30.3)$ \\
\hline Moderate & & $90(43.3)$ \\
\hline Severe & & $34(16.3)$ \\
\hline PSQI & $0.0-18.0$ & $6.18 \pm 4.356$ \\
\hline \multicolumn{3}{|l|}{ PSQI-Sleep quality } \\
\hline Good & & $113(54.3)$ \\
\hline Poor & & 95 (45.7) \\
\hline
\end{tabular}

Values are presented as mean \pm standard deviation or number $(\%)$. ICU, intensive care unit; PHQ, Patient Health Questionnaire; PSQI, Pittsburgh Sleep Quality Index. missing outcome data for survey participants $(n=12)$. The data of 208 participants were analyzed. The mean age of the study participants was $29 \pm 7.748$ years, $72.1 \%$ were male, $67.3 \%$ were nurses, $62 \%$ were working in intensive care units, 38\% were working in hospital wards, $62 \%$ were living alone and did not have children (Table 1). The number of participants who had a history of COVID-19 direct contact was 151, whereas 57 participants had no exposure.

The Fear of COVID-19 Scale, Patient Health Questionnaire and PSQI sleep quality assessment of the participants are included in Table 2. According to the results of the PHQ-9 test, moderate depression was the most frequently detected outcome among the participants ( $\mathrm{n}=90$, 43.3\%). The mean The Fear of COVID-19 Scale for all participants was $18.56 \pm 7.731$. The mean PSQI of patients was $6.18 \pm 4.356$. According to the sleep quality assessment, it was observed that $54.3 \%$ of the participants experienced good sleep quality and $45.7 \%$ of them had a poor sleep quality.

The comparison of participants with and without known exposures to patients with COVID-19 is given in Table 3. In the groups with and without COVID exposure, the COVID fear assessment scale did not differ significantly for the 1.-2.-3.-4.-5.-6.-7 questions ( $p>0.05)$.

Table 2. The Fear of COVID-19 Scale, Patient Health Questionnaire and Pittsburgh Sleep Quality Index assessment results of the participants

\begin{tabular}{lcc}
\hline \multicolumn{1}{c}{ Items } & Min-Max & Value \\
\hline Fear Scale 1st Question & $1.0-5.0$ & $3.19 \pm 1.455$ \\
Fear Scale 2nd Question & $1.0-5.0$ & $3.28 \pm 1.440$ \\
Fear Scale 3rd Question & $1.0-5.0$ & $1.98 \pm 1.286$ \\
Fear Scale 4th Question & $1.0-5.0$ & $2.77 \pm 1.416$ \\
Fear Scale 5th Question & $1.0-5.0$ & $2.92 \pm 1.409$ \\
Fear Scale 6th Question & $1.0-5.0$ & $2.42 \pm 1.462$ \\
Fear Scale 7th Question & $1.0-5.0$ & $2.19 \pm 1.340$ \\
Total score & $7.0-35.0$ & $18.56 \pm 7.731$ \\
PHQ-9 & & \\
Minimal & & $21(10.1)$ \\
Mild & & $63(30.3)$ \\
Moderate & & $90(43.3)$ \\
Severe & & $6.18 \pm 4.356$ \\
PSQI & & \\
PSQI- Sleep quality & & $113(54.3)$ \\
Good & & $95(45.7)$ \\
Poor &
\end{tabular}

Values are presented as mean \pm standard deviation or number (\%). PHQ, Patient Health Questionnaire; PSQI, Pittsburgh Sleep Quality Index. 
Table 3. The comparison of participants with and without knownpatients with COVID-19

\begin{tabular}{|c|c|c|c|}
\hline Items & COVID-19 direct contact $(-)$ & COVID-19 direct contact (+) & $p$ value \\
\hline \multicolumn{4}{|l|}{ The Fear of COVID-19 Scale } \\
\hline 1st Question & $3.12 \pm 1.55$ & $3.22 \pm 1.42$ & $0.727^{\mathrm{a}}$ \\
\hline 2nd Question & $3.12 \pm 1.51$ & $3.33 \pm 1.41$ & $0.381^{\mathrm{a}}$ \\
\hline 3rd Question & $2.02 \pm 1.38$ & $1.96 \pm 1.25$ & $0.949^{\mathrm{a}}$ \\
\hline 4th Question & $2.65 \pm 1.42$ & $2.81 \pm 1.42$ & $0.444^{\mathrm{a}}$ \\
\hline 5th Question & $2.89 \pm 1.35$ & $2.93 \pm 1.44$ & $0.873^{\mathrm{a}}$ \\
\hline 6th Question & $2.35 \pm 1.52$ & $2.44 \pm 1.44$ & $0.524^{\mathrm{a}}$ \\
\hline 7th Question & $2.19 \pm 1.41$ & $2.19 \pm 1.32$ & $0.871^{\mathrm{a}}$ \\
\hline Total score & $18.32 \pm 8.06$ & $18.65 \pm 7.63$ & $0.686^{\mathrm{a}}$ \\
\hline \multicolumn{4}{|l|}{ PHQ-9 } \\
\hline Minimal & $9(15.8)$ & $12(7.9)$ & $0.204^{b}$ \\
\hline Mild & $20(35.1)$ & $43(28.5)$ & \\
\hline Moderate & $20(35.1)$ & $70(46.4)$ & \\
\hline Severe & $8(14.0)$ & $26(17.2)$ & \\
\hline PSQI & $4.81 \pm 3.97(4.0)$ & $6.70 \pm 4.39(6.0)$ & $0.002^{\mathrm{a}}$ \\
\hline \multicolumn{4}{|l|}{ PSQI-Sleep quality } \\
\hline Good & $42(73.7)$ & $71(47.0)$ & $0.001^{b}$ \\
\hline Poor & $15(26.3)$ & $80(53.0)$ & \\
\hline Professional experience (yr) & $6.39 \pm 6.78(3.5)$ & $6.08 \pm 7.78(3.0)$ & $0.511^{\mathrm{a}}$ \\
\hline Anesthesiologists & $1(1.8)$ & $33(21.9)$ & $<0.001^{\mathrm{b}}$ \\
\hline Nurse & $31(54.4)$ & $109(72.2)$ & \\
\hline Nurses anesthetists & 25 (43.9) & $9(6.0)$ & \\
\hline \multicolumn{4}{|l|}{ Work area } \\
\hline $\mathrm{ICU}$ & $29(50.9)$ & $100(66.2)$ & $0.042^{b}$ \\
\hline Hospital ward & $28(49.1)$ & $51(33.8)$ & \\
\hline
\end{tabular}

Values are presented as mean \pm standard deviation (median) or number (\%).

ICU, intensive care unit; PHQ, Patient Health Questionnaire; PSQI, Pittsburgh Sleep Quality Index.

${ }^{\mathrm{a}} \mathrm{Mann}-$ Whitney $U$ test. ${ }^{\mathrm{b}} \mathrm{Chi}$-square test.

According to the PHQ-9 evaluation in the groups with and without COVID exposure, the rate of minimal, mild, moderate, or severe depression was not significantly different $(p>0.05)$. PSQI score and poor sleep quality were significantly higher in group with COVID-19 direct contact than the other group $(6.70 \pm 4.39$ vs. $4.81 \pm 3.97$ respectively, $p=0.002$ ).

Work experience did not differ significantly in groups with and without COVID contact $(p>0.05)$. The proportion of nurses and anesthesiologists was significantly higher in the group with COVID contact than the nonCOVID group $(p<0.001)$. The medical staff involved in treatment of COVID-19 patients were working in intensive care units with a rate of $66.2 \%$ and $33.8 \%$ in hospital wards.

The distribution of all three assessment scales according to anesthesiologists, nurses and other medical staff is shown in Table 4. PSQI was found significantly higher in nurses $(7.1 \pm 4.7, p<0.001)$. Nurses were the group with the highest deterioration in sleep quality $(53.6 \%, p=$
0.003). No significant difference was observed between other groups.

Comparison of three assessment scales between intensive care and hospital ward staff is shown in Table 5. Among the intensive care unit and hospital ward staff, The Fear of COVID-19 Scale total score did not differ significantly $(p>0.05)$. The total score of The Fear of COVID-19 Scale 3.-6.-7th questions in intensive care unit staff was significantly higher than hospital ward staff. According to PHQ-9 assessment, the rate of moderate-to-severe depressive symptoms was significantly higher in intensive care unit staff than the hospital ward staff $(p=$ 0.018)

In intensive care unit, PSQI score was found to be significantly higher than hospital ward co-workers (7.02 \pm 4.59 vs. $4.81 \pm 3.57$ respectively, $p=0.001$ ). According to PSQI index, the quality of sleep was significantly higher in hospital ward staff than in the intensive care unit (ICU) $(p=0.001)$.

The total score of The Fear of COVID-19 Scale, PSQI 
Table 4. Distribution of all three assessment scales between anesthesiologists, nurses and staff

\begin{tabular}{|c|c|c|c|c|}
\hline Items & Anesthesiologists & Nurses & Nurse anesthetists & $p$ value \\
\hline \multicolumn{5}{|c|}{ The Fear of COVID-19 Scale } \\
\hline 1st Question & $3.4 \pm 1.6$ & $3.2 \pm 1.4$ & $3.1 \pm 1.6$ & $0.623^{\mathrm{a}}$ \\
\hline 2nd Question & $3.1 \pm 1.6$ & $3.4 \pm 1.4$ & $3.1 \pm 1.6$ & $0.435^{\mathrm{a}}$ \\
\hline 3rd Question & $1.8 \pm 1.2$ & $2.1 \pm 1.3$ & $1.8 \pm 1.2$ & $0.431^{\mathrm{a}}$ \\
\hline 4th Question & $3.1 \pm 1.6$ & $2.7 \pm 1.4$ & $2.5 \pm 1.5$ & $0.278^{\mathrm{a}}$ \\
\hline 5th Question & $3.0 \pm 1.6$ & $2.9 \pm 1.3$ & $2.8 \pm 1.5$ & $0.861^{\mathrm{a}}$ \\
\hline 6th Question & $2.5 \pm 1.6$ & $2.5 \pm 1.4$ & $2.0 \pm 1.4$ & $0.147^{\mathrm{a}}$ \\
\hline 7th Question & $2.2 \pm 1.5$ & $2.3 \pm 1.3$ & $1.9 \pm 1.2$ & $0.168^{\mathrm{a}}$ \\
\hline Total score & $18.6 \pm 8.3$ & $18.9 \pm 7.6$ & $17.0 \pm 7.6$ & $0.381^{\mathrm{a}}$ \\
\hline \multicolumn{5}{|l|}{ PHQ-9 } \\
\hline Minimal & $5(14.7)$ & $8(5.7)$ & $8(23.5)$ & $0.458^{\mathrm{b}}$ \\
\hline Mild & $8(23.5)$ & $46(32.9)$ & $9(26.5)$ & \\
\hline Moderate & $13(38.2)$ & $62(44.3)$ & $15(44.1)$ & \\
\hline Severe & $8(23.5)$ & $24(17.1)$ & $2(5.9)$ & \\
\hline PSQI & $4.9 \pm 3.0$ & $7.1 \pm 4.7$ & $3.9 \pm 2.8$ & $<0.001^{\mathrm{a}}$ \\
\hline \multicolumn{5}{|c|}{ PSQI-Sleep quality } \\
\hline Good & $22(64.7)$ & $65(46.4)$ & $26(76.5)$ & $0.003^{b}$ \\
\hline Poor & $12(35.3)$ & $75(53.6)$ & 8 (23.5) & \\
\hline
\end{tabular}

Values are presented as mean \pm standard deviation or number $(\%)$.

PHQ, Patient Health Questionnaire; PSQI, Pittsburgh Sleep Quality Index.

${ }^{\mathrm{a}}$ Kruskal -Wallis (Mann - Whitney $U$ test). ${ }^{\mathrm{b}}$ Chi-square test.

Table 5. Comparison of three assessment scales between intensive care unit and hospital ward staff

\begin{tabular}{|c|c|c|c|}
\hline Items & $\mathrm{ICU}$ & Hospital ward & $p$ value \\
\hline \multicolumn{4}{|c|}{ The Fear of COVID-19 Scale } \\
\hline 1st Question & $3.24 \pm 1.42$ & $3.11 \pm 1.51$ & $0.575^{\mathrm{a}}$ \\
\hline 2nd Question & $3.42 \pm 1.39$ & $3.04 \pm 1.50$ & $0.072^{\mathrm{a}}$ \\
\hline 3rd Question & $2.12 \pm 1.28$ & $1.75 \pm 1.28$ & $0.007^{\mathrm{a}}$ \\
\hline 4th Question & $2.83 \pm 1.40$ & $2.67 \pm 1.44$ & $0.420^{\mathrm{a}}$ \\
\hline 5th Question & $2.89 \pm 1.38$ & $2.97 \pm 1.47$ & $0.653^{\mathrm{a}}$ \\
\hline 6th Question & $2.56 \pm 1.46$ & $2.18 \pm 1.44$ & $0.041^{\mathrm{a}}$ \\
\hline 7th Question & $2.36 \pm 1.35$ & $1.91 \pm 1.28$ & $0.009^{\mathrm{a}}$ \\
\hline Total score & $19.15 \pm 7.95$ & $17.59 \pm 7.31$ & $0.182^{\mathrm{a}}$ \\
\hline \multicolumn{4}{|l|}{ PHQ-9 } \\
\hline Minimal & $9(7.0)$ & $12(15.2)$ & $0.018^{\mathrm{b}}$ \\
\hline Mild & $35(27.1)$ & $28(35.4)$ & \\
\hline Moderate & $62(48.1)$ & $28(35.4)$ & \\
\hline Severe & $23(17.8)$ & $11(13.9)$ & \\
\hline PSQI & $7.02 \pm 4.59$ & $4.81 \pm 3.57$ & $0.001^{\mathrm{a}}$ \\
\hline \multicolumn{4}{|l|}{ PSQI-Sleep quality } \\
\hline Good & $59(45.7)$ & $54(68.4)$ & $0.001^{\mathrm{b}}$ \\
\hline Poor & $70(54.3)$ & 25 (31.6) & \\
\hline
\end{tabular}

Values are presented as mean \pm standard deviation or number (\%).

ICU, intensive care unit; PHQ, Patient Health Questionnaire; PSQI, Pittsburgh Sleep Quality Index.

${ }^{\mathrm{a}}$ Mann - Whitney $U$ test. ${ }^{\mathrm{b}}$ Chi-square test.

and the sleep quality did not differ significantly among men and women, participants with and without children and participants living alone or with someone else $(p>$ 0.05, Fig. 1).

The scores for the 2 nd and 5 th questions of The Fear of
COVID-19 Scale were significantly higher in participants living alone. The analysis for PHQ-9 assessment among participants ( $p>0.05$, Fig. 2). A significant negative correlation was observed between PSQI scores and age and the level of seniority ( $p<0.05$, Table 6). A significant 
positive correlation was observed between PSQI score and The Fear of COVID-19 Scale total score $(p<0.05)$.

\section{DISCUSSION}

In this cross-sectional study, questions were directed to hospital ward and ICU co-workers, and their fears, depression levels, and sleep disorders were determined during the COVID-19 outbreak. As a result, we observed that there was $43.3 \%$ moderate depression and $45.7 \%$ poor sleep quality among health care professionals. Moreover, younger participants, and ICU nurses exhibited a higher level of fear for COVID-19 disease.

A number of survey studies have been published evaluating the psychological effects of COVID-19 on healthcare professionals. Shacham et al. [16] evaluated the level of psychological distress experienced by Israeli dentists and dental hygienists and identified the factors that could

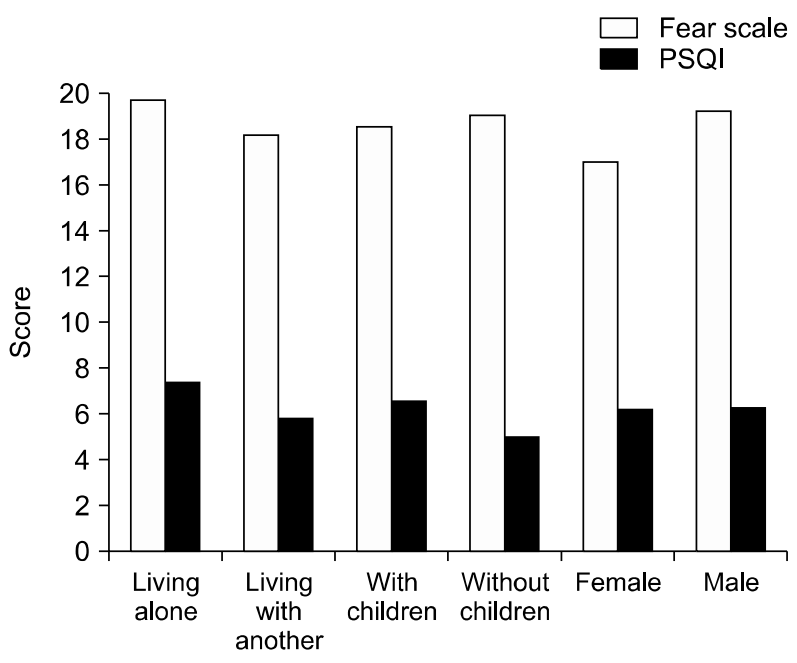

Fig. 1. The comparison of The Fear of COVID-19 Scale and Pittsburgh Sleep Quality Index (PSQI) among participants. be associated during the COVID-19 outbreak. This study indicated that the rate of psychological disorders increase among participants with comorbidity and more subjective overloads. The main difference was that the questionnaire was created by the authors. In our study, we revealed the psychological effects by directing the questions of 3 different questionnaires. All of them were valid and reliable.

In a survey study involving local Chinese residents aged $\geq 18$ years, the pandemic was reported to be associated with a mild stressful impact [17]. In this study, 52.1\% of the residents reported that they felt horrified. In our study, the fear of Coronavirus was evaluated with a previously validated test. Moreover, this scale was investigated for the validity and reliability in Italian population and a confirmatory factor analysis was performed [18]. The test was reported to be valid and reliable in assessing fear against

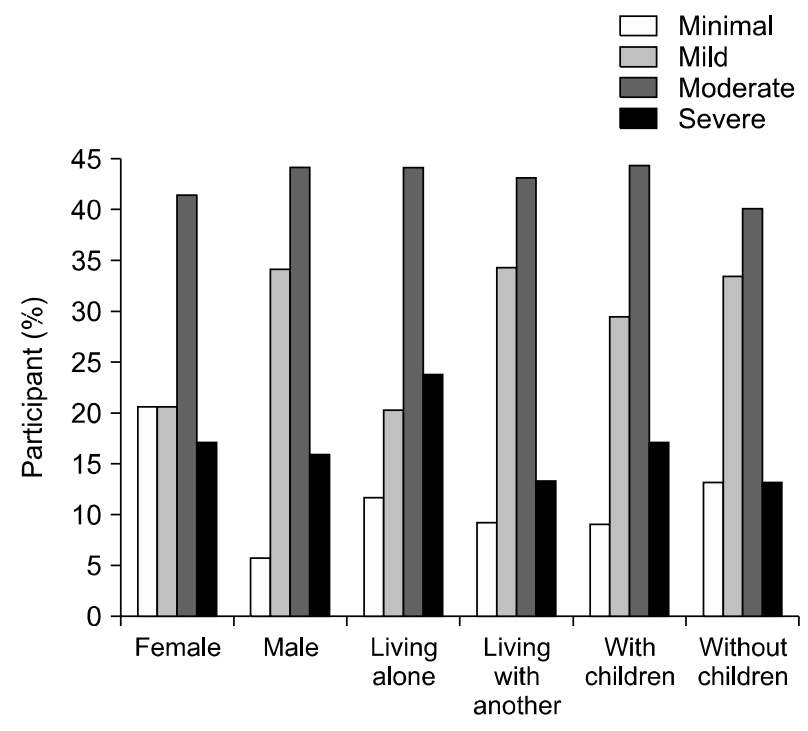

Fig. 2. The analysis for Patient Health Questionnaire-9 assessment among participants.

Table 6. Correlation analysis between PSQI score and The Fear of COVID-19 Scale

\begin{tabular}{|c|c|c|c|c|c|c|c|c|c|c|}
\hline Parameters & & PSQI & $\begin{array}{c}\text { 1st } \\
\text { Question }\end{array}$ & $\begin{array}{c}\text { 2nd } \\
\text { Question }\end{array}$ & $\begin{array}{c}\text { 3rd } \\
\text { Question }\end{array}$ & $\begin{array}{c}\text { 4th } \\
\text { Question }\end{array}$ & $\begin{array}{c}\text { 5th } \\
\text { Question }\end{array}$ & $\begin{array}{c}\text { 6th } \\
\text { Question }\end{array}$ & $\begin{array}{c}\text { 7th } \\
\text { Question }\end{array}$ & $\begin{array}{l}\text { Total } \\
\text { score }\end{array}$ \\
\hline \multirow[t]{2}{*}{ Age (yr) } & $r$ & -0.220 & 0.138 & 0.005 & 0.128 & 0.169 & 0.080 & 0.024 & 0.109 & 0.100 \\
\hline & $p$ & 0.001 & 0.047 & 0.944 & 0.066 & 0.015 & 0.251 & 0.731 & 0.116 & 0.149 \\
\hline \multirow{2}{*}{$\begin{array}{l}\text { Professional } \\
\text { experience }(y r)\end{array}$} & $r$ & -0.143 & 0.201 & 0.127 & 0.156 & 0.214 & 0.123 & 0.081 & 0.167 & 0.183 \\
\hline & $p$ & 0.041 & 0.004 & 0.072 & 0.026 & 0.002 & 0.081 & 0.252 & 0.017 & 0.009 \\
\hline \multirow[t]{2}{*}{ PSQI } & $r$ & & 0.208 & 0.286 & 0.275 & 0.267 & 0.267 & 0.404 & 0.280 & 0.349 \\
\hline & $p$ & & 0.003 & 0.000 & 0.000 & 0.000 & 0.000 & 0.000 & 0.000 & $<0.001$ \\
\hline
\end{tabular}

PSQI, Pittsburgh Sleep Quality Index.

Spearman correlation test. 
COVID 19. The unique feature of our study was that we revealed the fear of Coronavirus for healthcare workers, however we also determined the possible reasons. A significant positive correlation was found between advanced age and fear of COVID-19 and fear of losing life. However, the incidence of sleep disorders has not increased with advanced age. However, it was determined that the level of fear of ICU employees was higher than the hospital ward co-workers. The problematic aspect of patient medical condition becomes an important factor in the ICU. High mortality rate was reported for the COVID-19 patients receiving invasive mechanical ventilation in the ICU [19]. This situation causes higher fear rates in ICU employees. The paramount fear expressed by healthcare workers is that they will not only get sick, but also spread the virus to their patients and families. As such, many have opted to socially isolate themselves within their own homes.

In a survey study comparing the average values of fear, anxiety and depression between medical and administrative staff, the values were reported to be higher in healthcare providers [20]. Similarly, medical staff had higher sleep disorders in our study. However, in particular we observed a higher rate of sleep disorders among nurses, it was also revealed that the sleep quality was poor in this group. Most patients followed in intensive care units require advanced life support, including extracorporeal membrane oxygenation, continuous renal replacement therapy or mechanical ventilation in prone position. The nurses in the front line experience workload, longterm fatigue, threat of infection and disappointment with the death of the patients they care for. In a survey conducted with 85 ICU nurses, 45\% difficulty sleeping, 28\% nervousness, 59\% decreased appetite or indigestion were reported [21]. In our study, it was revealed that nurses frequently exhibit moderate depressive findings according to the PHQ-9 scale (44.3\%). Secondly, mild depressive findings were observed with a rate of $32.9 \%$. Depressive symptoms with rates ranging from $3.0 \%$ to $73.1 \%$ were reported during pandemics [5]. In our study, healthcare professionals indicated moderate to severe depressive symptoms. Moderate depression was detected in 43.3\% and severe depressive symptoms were observed in $16.3 \%$. It has been demonstrated that younger healthcare providers with less experience tend to be more depressed.

In a study involving 7,236 participants, Huang and
Zhao [22] reported that younger healthcare providers similarly had higher prevalence of anxiety disorders and depressive symptoms. We observed that depressive symptoms were associated with fear. The participants who are living alone, reported that they become more anxious with the news and stories on social media. On the other hand, there was no significant relationship between gender and fear, depression or sleep disturbance. We observed that $45.7 \%$ of the participants had poor sleep quality. Depression and anxiety have been reported to be associated with the development of insomnia in COVID-19 health workers [23]. In our study, we determined that the incidence of fear, anxiety, depressive symptoms and sleep disorder was higher in ICU co-workers. It was also revealed that sleep quality was worse in ICU employees. For this reason, it is important to provide psychological support to all ICU employees, in particular ICU nurses. Periodic training during the pandemic and early diagnosis of mental disorders will decrease the loss of workforce potential. Besides this may have a positive impact on COVID-19 patients.

\section{Limitations}

This is single-center study and the data of anesthesiology and intensive care employees were analyzed in our hospital. For this reason, the sample size was low. Future research involving a larger sample size is needed to further explore the potential psychological effects of COVID-19 for the healthcare providers.

\section{Conclusion}

This Cross-Sectional Study revealed that mental healthrelated conditions including depression, anxiety, fear, and sleep disorders may occur in healthcare workers during the COVID-19 outbreak. It was determined that intensive care unit nurses are at highest risk. Therefore, we concluded that in order to promote mental well-being in healthcare workers exposed to COVID-19, it is necessary to strengthen prevention and response strategies by providing immediate implementation of interventions and training healthcare professionals in mental aid and crisis management.

\section{- Conflicts of Interest}

No potential conflict of interest relevant to this article was reported. 


\section{Author Contributions}

Conceptualization: Kemal Tolga Saracoglu, Ayten Saracoglu. Data acquisition: Tahsin Simsek, Selime Kahraman, Elif Bombaci, Özlem Sezen. Formal analysis: Ayten Saracoglu. Funding: Recep Demirhan. Supervision: Recep Demirhan. Writing-original draft: Kemal Tolga Saracoglu, Ayten Saracoglu. Writing - review \& editing: Kemal Tolga Saracoglu, Ayten Saracoglu, Recep Demirhan.

\section{a ORCID}

Kemal Tolga Saracoglu

https://orcid.org/0000-0001-9470-7418

Tahsin Simsek https://orcid.org/0000-0002-3068-4998

Selime Kahraman https://orcid.org/0000-0002-0973-9624

Elif Bombaci https://orcid.org/0000-0002-9153-140X

Özlem Sezen https://orcid.org/0000-0002-2144-9224

Ayten Saracoglu https://orcid.org/0000-0002-1186-0933

Recep Demirhan https://orcid.org/0000-0003-4424-5918

\section{REFERENCES}

1. World Health Organization. WHO director-general's opening remarks at the media briefing on COVID-19-11 March 2020 [Internet]. Geneva: World Health Organization; 2020 [cited at 2020]. Available from: https://www.who.int/dg/ speeches/detail/who-director-general-s-opening-remarks-at-the-media-briefing-on-covid-19---11-march-2020.

2. Li S, Wang Y, Xue J, Zhao N, Zhu T. The impact of COVID-19 epidemic declaration on psychological consequences: a study on active Weibo users. Int J Environ Res Public Health 2020;17:2032.

3. El-Hage W, Hingray C, Lemogne C, Yrondi A, Brunault P, Bienvenu $\mathrm{T}$, et al. [Health professionals facing the coronavirus disease 2019 (COVID-19) pandemic: what are the mental health risks?] Encephale 2020;46(3 Suppl):S73-S80. French.

4. Kiecolt-Glaser JK, McGuire L, Robles TF, Glaser R. Emotions, morbidity, and mortality: new perspectives from psychoneuroimmunology. Annu Rev Psychol 2002;53:83-107.

5. Chew QH, Wei KC, Vasoo S, Chua HC, Sim K. Narrative synthesis of psychological and coping responses towards emerging infectious disease outbreaks in the general population: practical considerations for the COVID-19 pandemic. Singapore Med J 2020;61:350-356.

6. Tzur Bitan D, Grossman-Giron A, Bloch Y, Mayer Y, Shiffman $\mathrm{N}$, Mendlovic S. Fear of COVID-19 scale: psychometric characteristics, reliability and validity in the Israeli population. Psychiatry Res 2020;289:113100.

7. Sim K, Chua HC. The psychological impact of SARS: a matter of heart and mind. CMAJ 2004;170:811-812.
8. Wu P, Fang Y, Guan Z, Fan B, Kong J, Yao Z, et al. The psychological impact of the SARS epidemic on hospital employees in China: exposure, risk perception, and altruistic acceptance of risk. Can J Psychiatry 2009;54:302-311.

9. Levis B, Benedetti A, Thombs BD; DEPRESsion Screening Data (DEPRESSD) Collaboration. Accuracy of Patient Health Questionnaire-9 (PHQ-9) for screening to detect major depression: individual participant data meta-analysis. BMJ 2019;365:/1476.

10. Borghero F, Martínez V, Zitko P, Vöhringer PA, Cavada G, Rojas G. [Screening depressive episodes in adolescents. Validation of the Patient Health Questionnaire-9 (PHQ-9)]. Rev Med Chil 2018;146:479-486. Spanish.

11. Buysse DJ, Reynolds CF 3rd, Monk TH, Berman SR, Kupfer DJ. The Pittsburgh Sleep Quality Index: a new instrument for psychiatric practice and research. Psychiatry Res 1989;28:193213.

12. Ahorsu DK, Lin CY, Imani V, Saffari M, Griffiths MD, Pakpour $\mathrm{AH}$. The fear of COVID-19 scale: development and initial validation. Int I Ment Health Addict 2020. doi: 10.1007/ s11469-020-00270-8. [Epub ahead of print]

13. Tuck AN, Scribani MB, Grainger SD, Johns CA, Knight RQ. The 9-Item Patient Health Questionnaire (PHQ-9): an aid to assessment of patient-reported functional outcomes after spinal surgery. Spine J 2018;18:1398-1405.

14. Lee SY, Ju YJ, Lee JE, Kim YT, Hong SC, Choi YJ, et al. Factors associated with poor sleep quality in the Korean general population: providing information from the Korean version of the Pittsburgh Sleep Quality Index. J Affect Disord 2020;271:4958.

15. Zhu B, Xie M, Park CG, Kapella MC. Adaptation of the Pittsburgh Sleep Quality Index in Chinese adults with type 2 diabetes. J Chin Med Assoc 2018;81:242-247.

16. Shacham M, Hamama-Raz Y, Kolerman R, Mijiritsky O, Ben-Ezra M, Mijiritsky E. COVID-19 factors and psychological factors associated with elevated psychological distress among dentists and dental hygienists in Israel. Int J Environ Res Public Health 2020;17:2900.

17. Zhang Y, Ma ZF. Impact of the COVID-19 pandemic on mental health and quality of life among local residents in liaoning province, China: a cross-sectional study. Int J Environ Res Public Health 2020;17:2381.

18. Soraci P, Ferrari A, Abbiati FA, Del Fante E, De Pace R, Urso $\mathrm{A}$, et al. Validation and psychometric evaluation of the Italian version of the fear of COVID-19 scale. Int I Ment Health Addict 2020. doi: 10.1007/s11469-020-00277-1. [Epub ahead of print]

19. Zangrillo A, Beretta L, Scandroglio AM, Monti G, Fominskiy E, Colombo S, et al.; COVID-BioB Study Group. Characteristics, treatment, outcomes and cause of death of invasively ventilated patients with COVID-19 ARDS in Milan, Italy. Crit Care Resusc 2020. [Epub ahead of print]

20. Lu W, Wang H, Lin Y, Li L. Psychological status of medical 
workforce during the COVID-19 pandemic: a cross-sectional study. Psychiatry Res 2020. doi: 10.1016/j.psychres.2020. 112936.

21. Shen X, Zou X, Zhong X, Yan J, Li L. Psychological stress of ICU nurses in the time of COVID-19. Crit Care 2020;24:200.

22. Huang Y, Zhao N. Chinese mental health burden during the
COVID-19 pandemic. Asian J Psychiatr 2020;51:102052.

23. Li X, Yu H, Bian G, Hu Z, Liu X, Zhou Q, et al. Prevalence, risk factors, and clinical correlates of insomnia in volunteer and at home medical staff during the COVID-19. Brain Behav Immun 2020;87:140-141. 